\title{
Decarboxylation of 2,3-Dihydroxybenzoate to Catechol Supports Growth of Fermenting Bacteria
}

\author{
Angela Ostermann, Corinna Gallus, Bernhard Schink \\ Fakultät für Biologie, Universität Konstanz, Postfach 55 60, D-78434 Konstanz, Germany \\ Received: 16 April 1997 / Accepted: 9 May 1997
}

\begin{abstract}
Anaerobic enrichment cultures with 2,3-dihydroxybenzoate as sole source of energy and organic carbon yielded slow-growing cultures of fermenting bacteria. A culture derived from a marine inoculum, strain Pe23DHB, consisted of two morphotypes: spirilloid, highly motile bacteria (the predominant type), and very few long, rod-shaped bacteria. The culture was able to grow by decarboxylation of 2,3-dihydroxybenzoate to catechol. The decarboxylating activity was localized mainly in the cytosol; addition of avidin or of sodium salts had no effect on the decarboxylating activity in cell-free extracts. These results suggest that strain Pe23DHB did not conserve energy by a membrane-bound biotin-containing decarboxylase, creating a $\mathrm{Na}^{+}$-gradient across the cytoplasmic membrane. The energy conservation mechanism remains unknown at present.
\end{abstract}

Anaerobic degradation of hydroxybenzoates has been studied in detail through recent years. Bacteria degrading 3-hydroxybenzoate in methanogenic cocultures were isolated [22]; results of feeding experiments suggested that 3-hydroxybenzoate is degraded through benzoate after reductive dehydroxylation, and a similar pathway was proposed for nitrate-reducing bacteria, although the reduction reaction could never be shown in vitro [9]. 2-Hydroxybenzoate appears to enter the reductive benzoyl CoA pathway, retaining both functional groups until ring reduction [22]. Nitrate-reducing bacteria degrade 4-hydroxybenzoate by activation to 4-hydroxybenzoyl $\mathrm{CoA}$ and subsequent reductive dehydroxylation to benzoyl CoA [5].

The dihydroxybenzoates $\beta$-resorcylate (2,4-dihydroxybenzoate) and $\gamma$-resorcylate (2,6-dihydroxybenzoate) are degraded via decarboxylation to resorcinol [13, $21]$. Only the third isomer, $\alpha$-resorcylate (3,5-dihydroxybenzoate), is not decarboxylated; its degradation follows a separate, so far unknown pathway (Gallus and Schink, unpublished). Protocatechuate (3,4-dihydroxybenzoate) is degraded through activation to protocatechuyl-CoA and subsequent reductive dehydroxylation to benzoylCoA [6], analogous to the pathway of gentisate $(2,5-$ dihydroxybenzoate) degradation [7]. The often observed

Correspondence to: B. Schink decarboxylation of protocatechuate to catechol $[12,14]$ is probably a side reaction catalyzed by an enzyme system that operates in its main function in catechol activation [6].

Fermenting bacteria degrading 2,3-dihydroxybenzoate in methanogenic cocultures were first enriched by Tschech (unpublished) but were not investigated any further. In the present study, bacteria were enriched from marine sediments and sewage sludge with 2,3-dihydroxybenzoate in order to investigate the pathway of fermentative 2,3-dihydroxybenzoate degradation.

\section{Materials and Methods}

Sources of organisms. The enrichment cultures were inoculated with either anoxic, reduced marine sediments from channels in Venice, Italy, or anoxic sewage sludge from the municipal sewage plant in Konstanz, Germany.

Media and cultivation conditions. The medium for enrichment and cultivation was prepared as previously described [17, 23] and had the following composition (values in $\mathrm{g} / \mathrm{L}$ ): $\mathrm{KH}_{2} \mathrm{PO}_{4} 0.2, \mathrm{NH}_{4} \mathrm{Cl} 0.25, \mathrm{KCl}$ 0.5, $\mathrm{CaCl}_{2} \times 2 \mathrm{H}_{2} \mathrm{O} 0.15, \mathrm{MgCl}_{2} \times 6 \mathrm{H}_{2} \mathrm{O} 3.4, \mathrm{NaCl} 21.0$. It contained $30 \mathrm{~mm}$ sodium bicarbonate buffer, $1 \mathrm{~mm}$ sodium sulfide, trace element solution SL 10 [24], selenite-tungstate solution [20], and a mixture of seven vitamins [15]. 2,3-Dihydroxybenzoate was prepared as a neutral stock solution in oxygen-free water under nitrogen gas and filtersterilized into a gassed sterile serum bottle. Enrichment cultures were started with 5-10 mm 2,3-dihydroxybenzoate as sole substrate in the presence of about $200 \mu \mathrm{M}$ sodium dithionite as reducing agent. 


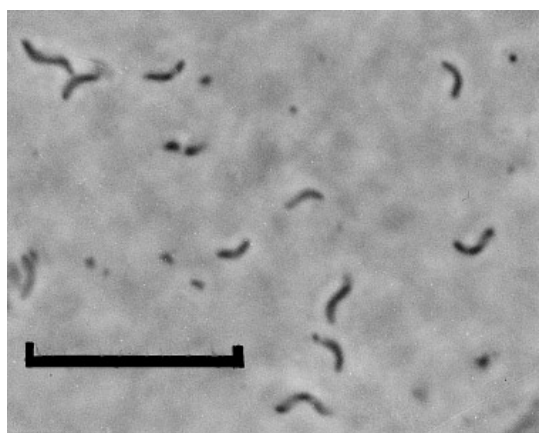

Fig. 1. Phase contrast photomicrograph of the binary mixed culture Pe23DHB. Bar equals $10 \mu \mathrm{m}$.

Isolation and cytological characterization. A binary mixed culture was obtained by repeated application of the agar shake culture method [15]. Gram staining was carried out according to [8], flagella staining according to [2]. Growth tests were done in duplicate in 100-ml serum bottles with $50 \mathrm{ml}$ culture under an $\mathrm{N}_{2} / \mathrm{CO}_{2}{ }^{-}$atmosphere. Samples were taken anoxically by syringe. Cultures for preparation of cell-free extracts were grown with $10 \mathrm{~mm}$ 2,3-dihydroxybenzoate, $1 \mathrm{~mm}$ acetate, $0.1 \%(\mathrm{wt} / \mathrm{vol})$ of prefermented yeast extract (prefermented as a $5 \%$ $\mathrm{wt} / \mathrm{vol}$ solution), and about $200 \mu \mathrm{M}$ sodium dithionite.

Chemical analysis. Acetate was measured by gas chromatography [17]. Aromatic compounds were quantified by reversed-phase, highpressure liquid chromatography (HPLC) [4]. As the mobile phase, a mixture of $60 \%$ of an aqueous $100 \mathrm{~mm}$ ammonium phosphate solution, $\mathrm{pH} 2.6$, and $40 \%$ methanol was used. The amount of protein was quantified by a variation of the biuret method with chemicals from Pierce (Rockford, IL, USA). Samples were mixed with the BCA Protein Assay Reagent and incubated for $30 \mathrm{~min}$ at a temperature of $60^{\circ} \mathrm{C}$. Comparison with the method of Bradford [3] showed no significant differences.

Cell harvesting and experiments with cell-free extracts. Cells were grown and refed repeatedly with $10 \mathrm{~mm}$ 2,3-dihydroxybenzoate. They were harvested by centrifugation under anoxic conditions and washed at least twice in $100 \mathrm{~mm}$ potassium phosphate buffer, $\mathrm{pH}$ 7.2. Cell-free extracts were prepared by disruption with a French Press and subsequent centrifugation at $12,000 \mathrm{~g}$. For one experiment, the extract was fractionated further by high-speed centrifugation (30 min at 250,000 g). The pellet containing the membranes was washed in $100 \mathrm{~mm}$ potassium phosphate buffer, $\mathrm{pH} 7.2$, and homogenized afterwards in the same buffer. Substrate degradation was followed in $5 \mathrm{ml}$ Hungate tubes. Samples were taken by syringe and preserved with $100 \mathrm{~mm} \mathrm{H}_{3} \mathrm{PO}_{4}$. In one experiment, $0.1 \mathrm{mg}$ avidin per $0.1 \mathrm{mg}$ protein was added.

All experiments were run at least in triplicate, with very little difference between the single runs.

\section{Results}

Enrichment and isolation. Enrichment cultures from marine sediments with 2,3-dihydroxybenzoate started substrate degradation and production of catechol after 2 weeks of incubation. 2,3-Dihydroxybenzoate was degraded in subcultures at a rate of about $1 \mathrm{~mm}$ per week; later, after several transfers, the rate increased to $5 \mathrm{~mm}$ per week. Catechol was never degraded further. Of these cultures, the culture Pesce23DHB was chosen for further investigation.

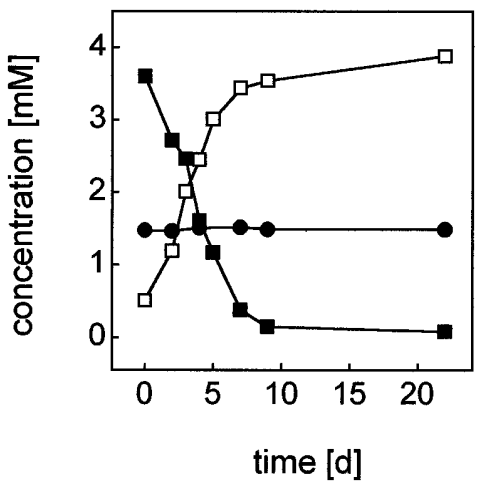

Fig. 2. Time course of the decarboxylation of 2,3-dihydroxybenzoate to catechol by culture Pe23DHB. $\mathbf{~ : ~ 2 , 3 - d i h y d r o x y b e n z o a t e , ~} \square$ : catechol, : acetate

A freshwater enrichment culture from an anaerobic sewage sludge sample degraded 2,3-dihydroxybenzoate much more slowly ( $0.4 \mathrm{~mm}$ per week at maximum). The culture produced no aromatic products except acetate and small portions of methane. This culture was not characterized further because of its slow growth.

Characterization. After applying the agar shake dilution method on the enrichment culture Pesce23DHB, the resulting culture Pe23DHB contained two organisms. The predominant type was a spirilloid Gram-negative bacterium (Fig. 1) that decarboxylated 2,3-dihydroxybenzoate or 3,4-dihydroxybenzoate, with concomitant production of catechol. It was motile by one polar flagellum. The culture also contained very few long, rod-shaped bacteria that could not be removed by agar shake dilutions, although various alternative growth conditions were applied. The long rods made up less than $0.1 \%$ of the total biomass when grown in mineral medium with 2,3dihydroxybenzoate (not visible in Fig. 1), but their number increased after addition of yeast extract or glucose.

Degradation of 2,3-dihydroxybenzoate and production of catechol are shown in Fig. 2. Acetate was added as a potential co-substrate for cell matter formation but was not consumed to a substantial extent. The cell yield was determined by direct gravimetry in 2-L cultures, and varied between 1.2 and $1.8 \mathrm{~g}$ dry cell mass per mol 2,3-dihydroxybenzoate degraded.

Experiments with cell-free extracts. The decarboxylation of 2,3-dihydroxybenzoate could be observed also in cell-free extracts and reached a reaction rate of $0.46 \mu \mathrm{mol}$ per min and $\mathrm{mg}$ protein, which was about five times higher than that in a growing culture $(0.068 \mu \mathrm{mol}$ per min and $\mathrm{mg}$ protein). A possible involvement of biotin in the reaction was checked for by measuring the effect of avidin on the turnover of 2,3-dihydroxybenzoate. As 


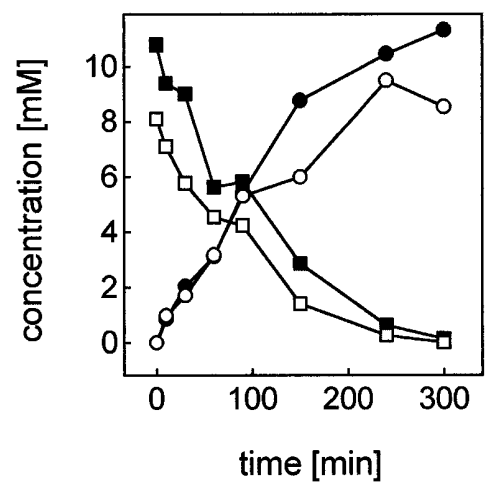

Fig. 3. Influence of avidin (about $0.1 \mathrm{mg} / 0.1 \mathrm{mg}$ protein) on the decarboxylation of 2,3-dihydroxybenzoate in cell-free extracts. Symbols: $\square$ : 2,3-dihydroxybenzoate; $\bigcirc$ : catechol. Filled symbols: controls without avidin addition.

shown in Fig. 3, the decarboxylation was not inhibited by avidin, suggesting that biotin was not involved in the reaction. $\mathrm{NaCl}$ was added at different concentrations (over a background concentration of $3 \mathrm{~mm} \mathrm{NaCl}$ ), but had no influence on the decrease of 2,3-dihydroxybenzoate in cell-free extracts. For localization of the decarboxylase activity, the cell-free extract was separated into a membrane and a cytosol fraction, and the turnover of 2,3dihydroxybenzoate was measured in both fractions (Fig. 4). The activity of the cytosol fraction $(0.42 \mu \mathrm{mol}$ per min) was about 20 times higher than that of the membrane fraction $(0.021 \mu \mathrm{mol}$ per min).

\section{Discussion}

In the present communication, we report on a binary mixed bacterial culture able to grow anaerobically by decarboxylation of 2,3-dihydroxybenzoate to catechol. Except for 2,3-dihydroxybenzoate and 3,4-dihydroxybenzoate, no other aromatic compound was decarboxylated, and growth with other substrates or substrate combinations could not be obtained. Growth with 2,3-dihydroxybenzoate was extremely slow, in accordance with the low energy change of the decarboxylation reaction in the range of $\Delta \mathrm{G}^{\circ},=-20 \mathrm{~kJ} / \mathrm{mol}$ (calculated, e.g., for decarboxylation of succinate to propionate [18]). This energy change is not sufficient for the formation of 1 ATP by substrate level phosphorylation, for which a $\Delta \mathrm{G}^{\circ}$, of at least $-70 \mathrm{~kJ} / \mathrm{mol}$ is required [19], but allows synthesis of only one-third of an ATP equivalent, the smallest amount of energy that can be exploited biochemically [16]. It has to be assumed, therefore, that energy is conserved by establishing an ion gradient across the cytoplasmic membrane rather than by conventional substrate level phosphorylation or electron transport phosphorylation processes.

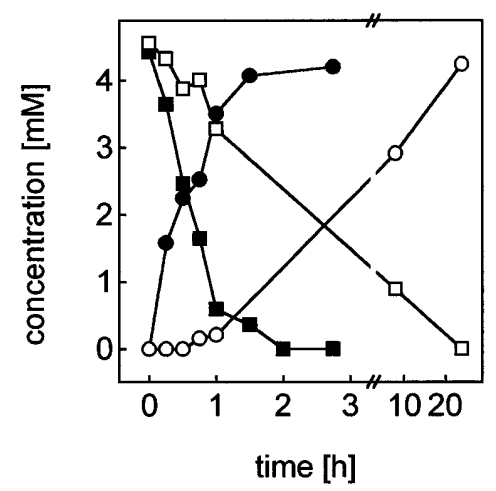

Fig. 4. Decarboxylation of 2,3-dihydroxybenzoate in the membrane and cytosol fraction. Open symbols refer to the membrane fraction, closed symbols to the cytosol fraction. $\square$ : 2,3-dihydroxybenzoate; $\bigcirc$ : catechol.

In recent years numerous anaerobic bacteria were found that conserve the free energy of decarboxylation in this way. Propionigenium modestum [11] and Malonomonas rubra [10] convert the energy into a $\mathrm{Na}^{+}$gradient by biotin-dependent, membrane-bound decarboxylases. The $\mathrm{Na}^{+}$gradient is used as a driving force to generate ATP at a 3:1 ratio.

In the present study on decarboxylation of 2,3dihydroxybenzoate, we found no indication of an influence of $\mathrm{Na}^{+}$-ions on the reaction in cell-free extracts, and the observed localization of the decarboxylation activity in the cytosol fraction also argues against a membraneintegrated sodium ion-pumping enzyme. Moreover, avidin did not inhibit the decarboxylation, indicating that biotin is not involved in the reaction. Thus, no evidence was found for the existence of a biotin-dependent decarboxylase which, analogous to the decarboxylases of M. rubra and P. modestum, could establish a $\mathrm{Na}^{+}-$ gradient across the cytoplasmic membrane.

A different model for energy conservation by decarboxylation was proposed for Oxalobacter formigenes [1], which grows by decarboxylation of oxalate to formate. Oxalobacter creates a proton gradient by means of an electrogenic oxalate/formate antiporter, thus creating a net proton gradient across the membrane that drives ATP synthesis. Such a mechanism of energy conservation through a secondary substrate/product transport system could underly energy conservation also in the dihydroxybenzoate-decarboxylating culture described here. Actually, the fact that cell-free extracts exhibited far higher substrate transformation rates than intact cell suspensions indicates that substrate transport was the rate-limiting step in intact cells and was perhaps connected with an energy-dependent process. However, since catechol should pass the membrane efficiently without specific transport, a secondary transport-dependent energy conservation 
system would depend only on substrate import, rendering the energy conservation rather inefficient, especially in the second half of a transformation process. This may explain the slow growth and low cell yields we obtained with the culture Pe23DHB.

We conclude that decarboxylation of 2,3-dihydroxybenzoate is coupled to energy conservation and growth in a new strain of strictly anaerobic bacteria, but that the mechanism of energy conservation in this organism is not yet understood.

\section{Literature Cited}

1. Anantharam V, Allison MJ, Maloney PC (1989) Oxalate: formate exchange, the basis for energy coupling in Oxalobacter. J Biol Chem 264:7244-7250

2. Blenden DC, Goldberg HS (1965) Silver impregnation stain for Leptospira and flagella. J Bacteriol 89:899-900

3. Bradford MM (1976) A rapid and sensitive method for the quantitation of microgram quantities of protein utilizing the principle of protein-dye binding. Anal Biochem 72:248-254

4. Brune A, Schink B (1990) Pyrogallol-to-phloroglucinol conversion and other hydroxyl-transfer reactions catalyzed by cell extracts of Pelobacter acidigallici. J Bacteriol 172:1070-1076

5. Glöckler R, Tschech A, Fuchs G (1989) Reductive dehydroxylation of 4-hydroxybenzoyl-CoA to benzoyl CoA in a denitrifying, phenol-degrading Pseudomonas species. FEBS Microbiol Lett 251:237-240

6. Gorny N, Schink B (1994a) Anaerobic degradation of catechol by Desulfobacterium sp. strain Cat2 proceeds via carboxylation to protocatechuate. Appl Eviron Microbiol 60:3396-3400

7. Gorny N, Schink B (1994b) Hydroquinone degradation via reductive dehydroxylation of gentisyl-CoA by a strictly anaerobic fermenting bacterium. Arch Microbiol 161:25-32

8. Gregersen T (1978) Rapid method for distinction of Gram-negative from Gram-positive bacteria. Eur J Appl Microbiol Biotechnol 5:123-127

9. Heising S, Brune A, Schink B (1991) Anaerobic degradation of 3-hydroxybenzoate by a newly isolated nitrate-reducing bacterium. FEMS Microbiol Lett 84:267-272

10. Hilbi H, Dehning I, Schink B, Dimroth P (1992) Malonate decarboxylase of Malonomonas rubra, a novel type of biotincontaining acetyl enzyme. Eur J Biochem 207:117-123

11. Hilpert W, Schink B, Dimroth P (1984) Life by a new decarboxyl- ation-dependent energy conservation mechanism with $\mathrm{Na}^{+}$as coupling ion. EMBO J 3:1665-1670

12. Kaiser JP, Hanselmann KW (1982) Aromatic chemicals through anaerobic microbial conversion of lignin monomers. Experientia 38:167-176

13. Kluge C, Tschech A, Fuchs G (1990) Anaerobic metabolism of resorcyclic acids ( $m$-dihydroxybenzoic acids) and resorcinol (1,3benzenediol) in a fermenting and in a denitrifying bacterium. Arch Microbiol 155:68-74

14. Kuever J, Kulmer J, Jannsen S, Fischer U, Blotevogel K-H (1993) Isolation and characterization of a new spore-forming sulfatereducing bacterium growing by complete oxidation of catechol. Arch Microbiol 159:282-288

15. Pfennig N (1978) Rhodocyclus purpureus gen. nov. sp. nov., a ring-shaped, vitamin $\mathrm{B}_{12}$-requiring member of the family Rhodospirillaceae. Int J Syst Bacteriol 28:283-288

16. Schink B (1990) Conservation of small amounts of energy in fermenting bacteria. In: Biotechnology focus 2, Finn RK, Praeve P (eds) Munich, Vienna, New York: Hanser Publishers, pp 63-89

17. Schink B, Pfennig N (1982a) Fermentation of trihydroxybenzenes by Pelobacter acidigallici gen. nov. spec. nov., a new strictly anaerobic non-sporing bacterium. Arch Microbiol 133:195-201

18. Schink B, Pfennig N (1982b) Propionigenium modestum gen. nov. sp. nov., a new strictly anaerobic bacterium growing on succinate. Arch Microbiol 133:209-216

19. Thauer RK, Jungermann K, Decker K (1977) Energy conservation of chemotrophic anaerobic bacteria. Bacteriol Rev 41:100-180

20. Tschech A, Pfennig N (1984) Growth yield increase linked to caffeate reduction in Acetobacterium woodii. Arch Microbiol 137:163-167

21. Tschech A, Schink B (1985) Fermentative degradation of resorcinol and resorcylic acids. Arch Microbiol 143:52-59

22. Tschech A, Schink B (1986) Fermentative degradation of monohydroxybenzoates by defined cocultures. Arch Microbiol 145:396402

23. Widdel F, Pfennig N (1981) Studies on dissimilatory sulfatereducing bacteria that decompose fatty acids. I. Isolation of new sulfate-reducing bacteria enriched with acetate from saline environments. Description of Desulfobacter postgatei gen. nov., sp. nov. Arch Microbiol 129:395-400

24. Widdel F, Kohring GW, Mayer F (1983) Studies on dissimilatory sulfate-reducing bacteria that decompose fatty acids. III. Characterization of the filamentous gliding Desulfonema limicola gen. nov. sp. nov., and Desulfonema magnum sp. nov. Arch Microbiol 134:286-294 